\title{
A Smart and Predictive Heating System Using Data Fusion Based on the Belief Theory
}

\author{
Améni MAKHLOUF ${ }^{1,2}$ * , Bruno MARHIC ${ }^{1}$, Laurent DELAHOCHE ${ }^{1}$, \\ Arnaud CLÉRENTIN ${ }^{1}$, Hassani MESSAOUD ${ }^{2}$ \\ ${ }^{1}$ Laboratoire des Technologies Innovantes (LTI) EA 3899, Dpt. Informatique, \\ Avenue des Facultés le Bailly, 80000 Amiens Cedex 1, France \\ makhlouf.ameni@gmail.com, (*corresponding author) \\ ${ }^{2}$ Laboratoire de Recherche en Automatique, \\ Traitement du Signal et Image (LARATSI), ENIM, \\ Rue Ibn El Jazzar, 5000 Monastir, Tunisia
}

\begin{abstract}
This paper investigates the way to model and handle the contextual data uncertainties in order to design a smart heating system that reduces energy consumption. To achieve this, we propose in this paper a data fusion system which provides a trend hypothesis (contextual and near future prediction) with its associated belief. The data to be fused are essentially the occupant's habits, the weather forecast as well as the notion of thermal comfort associated to the occupant's activities. Since the data are uncertain, erroneous and heterogeneous, we propose a multilevel data fusion system based on the belief theory of Dempster-Shafer for data combination and the Transferable Belief Model (TBM) for making the decision which will be a challenge. Despite the data complexity, the simulations are very satisfactory in terms of reducing energy consumption.
\end{abstract}

Keywords: multilevel fusion, dempster-shafer theory, modelling uncertainty, energy saving, building management system.

\section{Introduction}

Buildings are responsible for $40 \%$ of energy consumption and $36 \%$ of $\mathrm{CO}_{2}$ emissions in the EU. The European Performance of Building Directive has set a target for all new buildings to be near zero-energy consumption by 2020 . In France thermal standards RT2012 have been set to reach these directives. The RT2012 [14] aims to decrease the level of $\mathrm{CO}_{2}$ emission for new buildings while the RT2015 aims to optimise and to reduce the energy consumption. The reduction of energy consumption in buildings, called the EE (Energetic Efficiency), depends on a set of elements such as the building's orientation, the geometry, the insulation, the thermal mass and also of AEE (Active Energetic Efficiency) elements, such as intelligent lighting and of course the conception of a better performing HVAC (Heating, Ventilating, and Air Conditioning) regulation and management. In Northern Europe, developing high performance and intelligent heating systems has become crucial in order to reduce energy consumption [2]. In France, electric heating is the main energy consumer in buildings with $70 \%$ represented by residential housing [16]; which justifies the development and the integration of smart-heating regulators.

Many researchers try to find the most adapted solutions for energy management in buildings. Some are focused on energy consumption reduction in public buildings $[3,8 \& 12]$. In [13] the authors deal with reducing the daily energy costs in household management without affecting the user's comfort; they consider the occupant's expectations as well as the physical constraints, such as energy prices and limitations of the renewable energy power. Other projects $[4,15]$ have been conducted in this context to evaluate the performance of existing control systems, to test new approaches and their influence on energy consumption as well as on the daily lives of the occupants. In $[6,7]$ the Artificial Neural Networks (ANN) are used to analyse data from different sensors in order to maintain a stable and comfortable temperature in the building. In [11] the researchers have adapted a neuralfuzzy system for the HVAC system in order to collect internal data dynamically and automatically and regulate the temperature to reach an optimal level of thermal comfort.

A building is a dynamic system; it is in permanent interaction with its internal and external environment. Its modelling depends on internal factors, such as occupation, thermal convection between the different rooms and thermal transfer due to the lighting and electrical appliances, and external ones such as the exterior temperature, the wind speed and direction and the orientation of the room with respect to the sun. These considerations lead us to incorporate the meteorological impact on the building in order to 
propose a model that is as complete as possible. Weather forecasts have been integrated in the regulation of heating systems based on a predictive control strategy [17] for an automated room (IRA: Integrated Room Automation). The different simulations show that the integration of data from weather forecasts with a stochastic MPC approach provides interesting results in terms of energy savings.

Another significant aspect is the presence of the occupant and the nature of his activity in the building. These are essential factors as they contribute directly to the energy efficiency of the building. The authors in [15] have presented the occupation of the building as a dynamic vector that will be integrated in the cost function of the predictive system. In [21] the authors have presented an interesting method to handle the occupancy of housing. It integrates the fact that the occupancy can be perturbed and deviate from any given planning.

In this paper the reader will see how we tackled and succeeded in reducing a heating system's energy consumption by processing and fusing heterogeneous numerical data in order to take predictive and sensible decisions whilst maintaining the user's desired comfort level.

The paper is organized as follows: Section 2 rapidly outlines our contribution. Section 3 briefly introduces the belief theory and the TBM model. In section 4 our approach is detailed. Several simulation case studies are presented and discussed in section 5. Finally in section 6 we discuss the reliability of the proposed system by comparing it to a weighted mean method. Then we conclude the paper.

\section{Contributions and Objectives}

The main objective of the proposed method is the reduction of energy consumption by maintaining the occupant's desired comfort level. We will focus on smart homes equipped with several sensors. For simplicity and without loss of generality we will limit our study to the case of only one occupant in one room. We will use the belief functions to propose a data fusion system that integrates data from weather forecasts, occupant's activity, clothing as well as the room's occupancy. The fusion of the cited data will be translated into contextual consignments, which will be introduced into a control system that regulates the heating system.
The main contribution of this article is to propose a solution to process and to fuse heterogeneous numerical data issued from sensors. The decision making that we propose is also semantic (not numerical) so that the appropriate uncertainty is calculated contrarily to the case of probabilistic or Fuzzy methods. This is also an interesting part of our contribution as the quality of the decision making has to be taken into account to make an appropriate regulation of the Smart and Predictive Heating System SPHS.

\section{Preliminary Notions}

\subsection{Dempster-Shafer Theory}

The Dempster-Shafer Theory known as the evidence theory was introduced by Dempster in 1967 and improved by Shafer in 1976 [19]. It is a powerful mathematical tool to model and fuse uncertain and inaccurate data. The evidence theory is widely applied in different fields such as word sense disambiguation, postal addresses recognition and deficiency detection in sensors [9, $10 \& 12]$. The asset of this theory is its flexibility to model the information and its ability to represent the ignorance with a clearer and more efficient method than the probabilistic functions. We define the Frame of Discernment (FoD) $\Omega$ as a set of $N$ hypotheses that represent the exhaustive and exclusive solutions to the problem.

$$
\begin{aligned}
& \Omega=\left\{H_{1}, H_{2}, \ldots, H_{N}\right\} \\
& \text { with } H_{i} \cap H_{j}=\varnothing ; \forall i, j \in N \text { and } i \neq j
\end{aligned}
$$

We define the power set $2^{\Omega}=\{\mathrm{A} / \mathrm{A} \subseteq \Omega\}$ which presents the hypothesis and all their disjunctions $2^{\Omega}=\left\{\varnothing, \mathrm{H}_{1}, \ldots, \mathrm{H}_{\mathrm{N}}, \mathrm{H}_{1} \cup \mathrm{H}_{2}, \ldots, \Omega\right\}$. Thus we present the element that characterises the theory of evidence i.e. the mass function or the Basic Belief Assignment (BBA) of each element of $2^{\Omega}$ by:

$$
\begin{aligned}
& m: 2^{\Omega} \rightarrow[0,1] \\
& A \rightarrow m(A) \\
& \text { with } \sum_{A \subseteq \Omega} m(A)=1
\end{aligned}
$$

\subsection{The Transferable Belief Model}

In this article we will consider a particular aspect of the evidence theory; the Transferable Belief Model (TBM) which is a model for quantifying our degree of belief that some propositions of the power set $2^{\Omega}$ are true and that only one of the elementary propositions of 
$\Omega$ is true [20]. The mass of conflict in the TBM can be $\mathrm{m}(\varnothing)>0$ unlike the theory of belief that supposes that $m(\varnothing)=0$. The TBM is based on a two-level model: the first level is the credal level where the beliefs are modelled, combined and updated, whereas the second level is the pignistic level where the beliefs are transformed to pignistic probability (BetP) and used to make a decision [20]. To fuse different sources of information, we combine beliefs linked to each expert with a conjunctive combination known as the TBM conjunctive rule $\bigcirc$.We associate the mass $m_{1}$ to the source 1 of information (i.e. expert 1) and the $\mathrm{m}_{2}$ to the source 2, the combination is as follows:

$$
\begin{aligned}
& \forall H_{i} \in 2^{\Omega} ; \\
& \mathrm{m}_{1{ }_{2}}\left(\mathrm{H}_{\mathrm{i}}\right)=\mathrm{m}_{1,2}\left(\mathrm{H}_{\mathrm{i}}\right) \\
& m_{1,2}\left(H_{i}\right)=\sum_{A \cap B=H_{i}} M_{1}(A) . m_{2}(B)
\end{aligned}
$$

And the mass of conflict is defined as:

$\mathrm{m}_{1,2}(\emptyset)=\sum_{\mathrm{A} \cap \mathrm{B}=\emptyset} \mathrm{m}_{1}(\mathrm{~A}) \cdot \mathrm{m}_{2}(\mathrm{~B})$

The pignistic probability is given by [21]:

$$
\operatorname{BetP}(Y)=\sum_{A \subseteq \Omega, Y \in A} \frac{m(A)}{|A|(1-m(\varnothing))}
$$

In our current study, we will consider the maximum of pignistic probability to make a decision [33], as it is the best compromise between the maximum of belief and the maximum of plausibility.

\subsection{Discounting}

The information given by each source has a degree of reliability, therefore we introduce the reliability index $\alpha \in[0,1]$ [20]. This discounting technique allows us to determine the credibility of the masses provided by an expert:

$$
\left\{\begin{array}{l}
m(A)=(1-\alpha) m(A) \\
m(\Omega)=\alpha+m(\Omega)(1-\alpha)
\end{array}\right.
$$

\section{Description of the Method}

The objective of this study is to ensure the thermal comfort of the occupant and reduce energy consumption. To do so, we need to find the best compromise to manage these two paradoxical criteria. The theory of evidence is used to analyse and merge different data in order to propose a decision (temperature trend) that will be a contextual reference. The contextual temperature trend is sent to the (SPHS). The Control aspect is not discussed in this paper.

\subsection{Proposed model}

As discussed in section 2, our habitat model is equipped with several sensors which inform about the occupancy prediction, the activity and the thermal comfort state in the house, as well as the weather forecast. This information has a direct influence on the "Comfort Mode" switch of the SPHS. When the "Comfort Mode" is off, this signifies that the system will, a priori, if nothing changes, reach the "Eco Mode" (usually "Comfort Mode" minus $3^{\circ} \mathrm{C}$ ). We propose a multilevel fusion system of previous data presented in the structural diagram given by Figure 1. Our design is in two fusion levels; the first one has for objective to associate the different sources of information, and the second

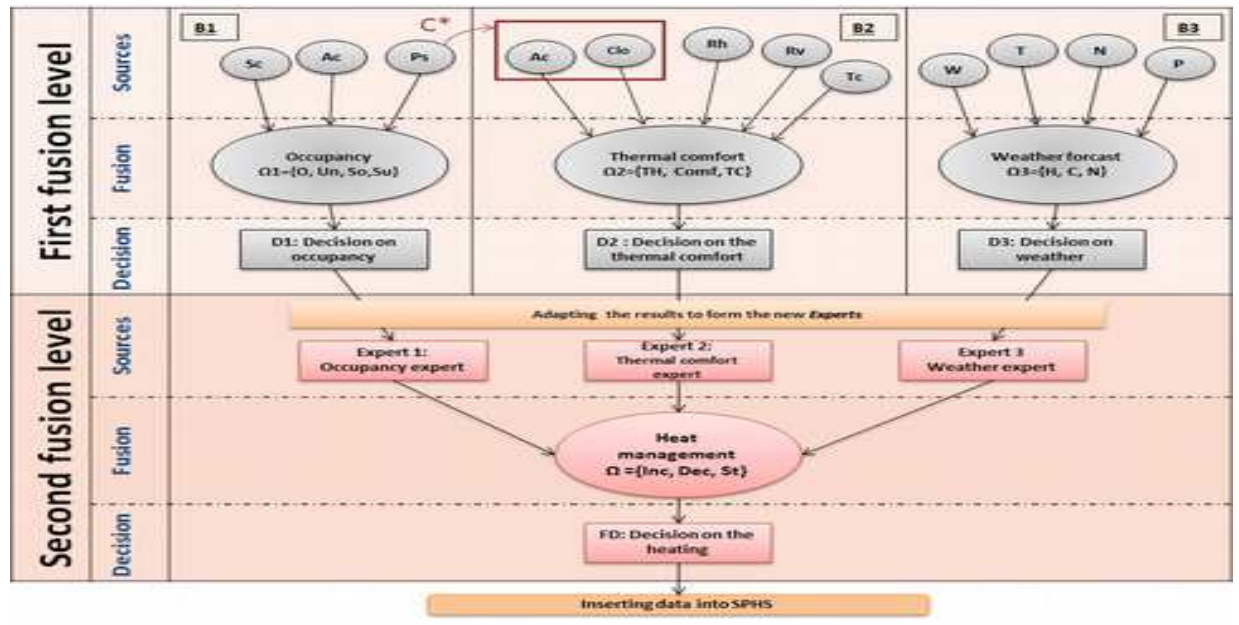

Figure 1. Structural diagram of fusion (see Table 3 for abbreviations)

$\mathrm{C}^{*}$ : A condition for the expert's activity and clothing that will only be considered in the fusion system if the habitation is occupied; i.e. $\mathrm{E}=1$ given by the Presence sensor (Ps) 
Table 1. Abbreviations used in the Figure1

\begin{tabular}{|c|c|c|c|c|}
\hline Sources & B1: Occupancy & B2: Thermal comfort & B3: Weather forecast & Heat management \\
\hline $\begin{array}{l}\text { The inputs: } \\
\text { Sources of } \\
\text { the fusion } \\
\text { system }\end{array}$ & $\begin{array}{l}\text { Sc: Schedule } \\
\text { Ac: the occupant's } \\
\text { activity } \\
\text { Ps :Presence sensor: } \\
\text { In/Out (E) } \\
\end{array}$ & $\begin{array}{l}\text { Tc: comfort Temperature }\left({ }^{\circ} \mathrm{C}\right) \\
\text { Rv: Relative air velocity }(\mathrm{m} / \mathrm{s}) \\
\text { Rh: Relative humidity }(\%) \\
\text { Clo: Clothing (clo) } \\
\text { Ac: the occupant's activity }\end{array}$ & $\begin{array}{l}\text { T: Temperature }\left({ }^{\circ} \mathrm{C}\right) \\
\text { W: W }(\mathrm{Km} / \mathrm{h}) \\
\mathrm{N}: \text { Nebulosity }(\%) \\
\text { P: Precipitation }(\mathrm{mm})\end{array}$ & $\begin{array}{l}\text { Expert1: Occupancy expert } \\
\text { Expert2: Thermal comfort } \\
\text { expert } \\
\text { Expert3: Weather expert }\end{array}$ \\
\hline $\begin{array}{l}\text { The outputs: } \\
\text { Frame of } \\
\text { Discernment }\end{array}$ & $\begin{array}{l}\Omega 1=\{\mathrm{O}, \mathrm{Un}, \mathrm{So}, \mathrm{Su}\} \\
\mathrm{O}: \text { Occupied } \\
\text { Un: Unoccupied } \\
\text { So: Soon occupied } \\
\text { Su: Soon unoccupied }\end{array}$ & $\begin{array}{l}\Omega 2=\{\mathrm{TC}, \text { Comf }, \mathrm{TH}\} \\
\text { TC: Too cold } \\
\text { Comf: Comfortable } \\
\text { TH: Too hot }\end{array}$ & $\begin{array}{l}\Omega 3=\{\mathrm{H}, \mathrm{C}, \mathrm{N}\} \\
\mathrm{H}: \text { Hot } \\
\text { C: Cold } \\
\mathrm{N}: \text { Nice }\end{array}$ & $\begin{array}{l}\Omega=\{\text { Inc, Dec, St }\} \\
\text { Inc: Increase } \\
\text { Dec: Decrease } \\
\text { St: Stable }\end{array}$ \\
\hline
\end{tabular}

one aims to generate the "temperature trend" that will be inserted into the SPHS. The first level is subdivided into three blocks (B1, B2 and $\mathrm{B} 3$ ). We proceed to agglomerate data for each block independently. Each block is subdivided into three parts: the sources, the fusion, and the decision part. Every source of information gives an exhaustive and an exclusive set of masses (BBA §3). We fuse the different masses with the conjunctive combination rule (equation 5). Then, the decision will be made according to the maximum of pignistic probability criteria (equation 7). In section 4.2, we will present the details of each fusion block B1, B2, and B3. Moreover, each block $B_{i}$ gives a decision $D_{i}$ with $i \in\{1,2,3\}$, so these three decisions will give us the essential information to model the new sets of masses for each expert in the second level. All this information represents the pignistic probabilities of each singleton associated with its respective FoD. The final decision (FD) results from the fusion with the TBM of the sets of masses of the three sources (the occupancy expert, the comfort expert and the weather expert). The FD produces a contextual and predictive trend (i.e. reference) that will be the input of the SPHS.

\subsection{First fusion level}

Every fusion block in the first level (see Figure 1) is composed of several sources of information that represent the experts for each block (i.e. gives its opinion on the data and defines the BBA). The input of the first fusion level is the masses linked to each element of their FoD (i.e: $\Omega 1, \Omega 2$ and $\Omega 3$, see in Table 1). We define these masses arbitrarily and we respect the intervals and logical values specified in the scientific literature in regards to each expert.

\subsubsection{Block B1: Occupancy}

B1 is the occupancy fusion block; it has three independent information sources or experts: the in/out sensor, the weekly schedule and the activity of occupant sensors known as expert occupancy 1, 2 and 3 respectively. The fusion of the three experts gives a decision on the occupancy state of the room. This information will be used later in the second fusion Level section. We will detail each expert of the block B1 with $\mathrm{FoD}, \Omega 1=\{\mathrm{O}, \mathrm{Un}, \mathrm{So}, \mathrm{Su}\}$ that means \{Occupied, Unoccupied, Soon occupied, Soon unoccupied\}.

Expert occupancy 1: The information is provided by a passive infrared sensor (PIR sensor). This expert gives its opinion based on the output $(\mathrm{E})$ of the presence sensor (Ps): $(\mathrm{E}=1$ if the room is occupied and $\mathrm{E}=0$ if not)

Expert occupancy 2: presents its opinion based on the variation of habits revealed in the fixed weekly schedule. This schedule is sampled every 30 minutes throughout the week and the masses are assigned depending on the prior presence of the occupant in the house.

The Monday's BBAs according to the weekly schedule are presented in Figure 2. The mass distribution between 7 and 8.30 a.m undergoes several variations. The mass distributions are adapted to the different unexpected events (schedule changes). In addition, the room must be preheated if the occupant is coming home soon and we need to turn down the heat slowly if he's leaving the room soon. This will be treated in a further work with a machine learning system. Meanwhile, if we have unexpected events (i.e. the occupant comes home earlier or later than expected...) that we obviously didn't plan in the schedule; this will generate a disturbance when we fuse the three experts which will be modelled by a conflict 


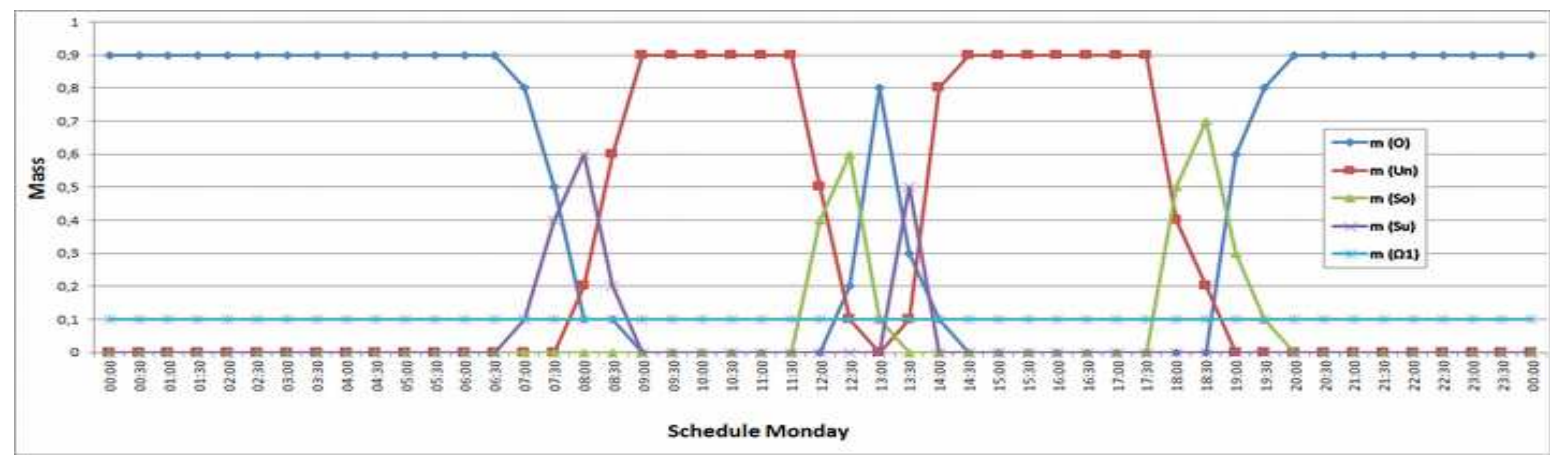

Figure 2. The Monday schedule

mass. Despite this disruption, we will succeed in obtaining a satisfactory decision on the state of occupancy of the room, as the DempsterShafer theory, and specifically the TBM, has the adequacy to solve this problem. (Simulation examples are in section 5).

Expert occupancy 3: We have different sensors installed in the house that provide the required information to identify the occupant's activity. These sensors will give us an idea about the activity of the occupant when he's at home, it can inform us if he's getting ready to leave or if he's staying home for a long time.

\subsubsection{Block B2: Thermal comfort}

The thermal comfort is defined in [1] as "a state of satisfaction of the body against the thermal environment". The concept of comfort varies from one person to another and different statistic studies were carried out on representative samples of people to establish the different aspects of the thermal comfort criteria. Thus, in ISO 7730-2005 «Ergonomics of the thermal Environment --Analytical determination and interpretation of thermal comfort using the Predicted Mean Vote (PMV) and the Predicted Percentage of Dissatisfied (PPD) indices and local thermal comfort criteria» we can distinguish the intervals of different environmental features that define the state of comfort or discomfort of a person in a given ambience. We use different sensors to gather the information for each source.
The room temperature is measured by a thermometer. The relative velocity and humidity is given by the controlled mechanical ventilation (CMV) installed in the room. The clothing expert, however, is provided by ISO 7730 - 2005, according to the season and the activity information. In our study, the following inputs (experts) of $\mathrm{B} 2$ are: -- The temperature of comfort (Tc) in Celsius --The relative humidity $(\mathrm{Rh})$ in percentage --The relative air velocity $(\mathrm{Rv})$ in $\mathrm{m} / \mathrm{s}$ --The clothing (Clo) in Clo index from clothingand the activity (Ac) in met index from human metabolic activity (ISO 7730-2005). The FoD for $\mathrm{B} 2$ is $\Omega 2=\{\mathrm{TC}, \mathrm{Comf}, \mathrm{TH}\}$, meaning \{Too-Cold, Comfortable, Too-Hot\}. Considering the values revealed in ISO 7730-2005 we transform the numeric data of the different parameters of comfort into a set of masses assigned to our FoD as shown in Figure 3.

\subsubsection{Block B3: Weather forecast}

We will use the data, provided by the latest version of the weather model AROME [18] for the fusion of block B3. The nebulosity influences the temperature in the building and outdoors during the day and the night. Thus, our «temperature expert» will depend on the variation of the nebulosity. We specify an interval for each temperature value and we attribute a function to define the masses in that interval. Since AROME gives new prediction values every 3 hours, the fusion for block B3 will be repeated every 3 hours.

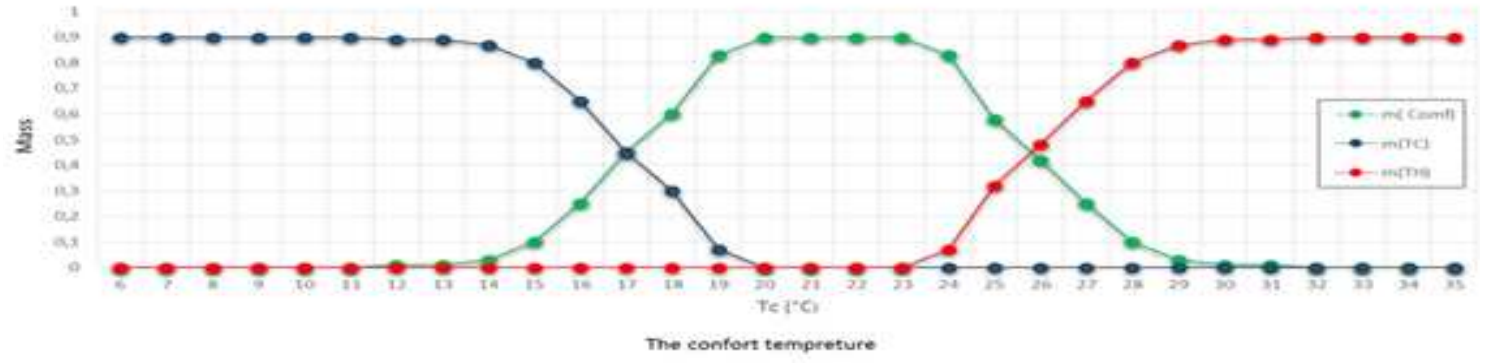

Figure 3. Masses assigned to the temperature of comfort expert 


\subsection{Second Fusion Level}

The second fusion level consists of the fusion of the occupancy expert, the thermal comfort expert and the weather expert, resulting from the fusion blocks (B1, B2 and B3). We present the data processing to define the new sets of masses (BBA) as follows: we assign each previous result to the FoD of the heating system: $\Omega=\{$ Inc, Dec, St , means \{'Increase the heating', 'Decrease the heating', 'stay Stable' $\}$. A mass function is defined based on the previous pignistic probabilities and the mass of ignorance $\mathrm{m}(\Omega \mathrm{i}), \mathrm{i} \in\{1,2,3\}$ resulting from the first fusion. The second level of fusion does not produce a temperature reference but only a predictive trend on the temperature (next sampling time). In other words, the data fusion system prepares the SPHS to the next event according to the indoor temperature reference, e.g. pre-heating, soft transition from "EcoMode" to "Comfort-Mode", temperature reference modulation according to the occupant's activity.

For example, we present the set of masses $\left(m_{\text {weather }}\right)$ generated from the weather forecast expert which gives its opinion on the state of occupancy in the first fusion level:

$$
\left\{\begin{array}{l}
m_{\text {weather }}(\operatorname{Inc})=\operatorname{BetP}(C){ }^{m}\left(\Omega_{3}\right) / 3 \\
m_{\text {weather }}(\operatorname{Dec})=\operatorname{BetP}(H)-m\left(\Omega_{3}\right) / 3 \\
m_{\text {weather }}(S t)=\operatorname{BetP}(N)-{ }^{m\left(\Omega_{3}\right) / 3} \\
m_{\text {weather }}(\Omega)=1-\left(m_{w}(\operatorname{Inc})+m_{w}(\text { Dec })+m_{w}(S t)\right)
\end{array}\right.
$$

\section{Case studies-Simulation Results}

In this section, we will show the efficiency and reliability of the approach we proposed to fuse heterogeneous, erroneous and uncertain data. The final decision provides a contextual temperature trend which is a kind of predictive temperature reference, in order to manage the SPHS. The main idea is to perform different simulations in a one day period to test the performance of our fusion system. We will consider "Monday" as a regular workday of the week during which unexpected events could of course occur. In addition, we will consider the schedule presented in fig 2 as our data base for the occupancy planning given by the occupant, and we will vary the other parameters such as the weather and the thermal comfort parameter to test their influence on the fusion system. For each scenario, we will define the different parameters' values for each fusion block (B1, B2 and B3) to obtain the results of the first fusion level. Then, the masses for the second fusion level will be automatically generated for each expert as stated in section 4.3.

\subsection{Scenario no. 1}

In this scenario the occupant is getting ready to go outside. The data of different sources are presented in Table 4.

Table 4. First scenario's parameters

\begin{tabular}{|l|l|l|}
\hline B1:Occupancy & $\begin{array}{l}\mathrm{B} 2 \text { : Thermal } \\
\text { comfort }\end{array}$ & $\begin{array}{c}\text { B3: Weather } \\
\text { forecast }\end{array}$ \\
\hline Day: Monday & $\mathrm{Tc}=22^{\circ} \mathrm{C}$, & $\mathrm{T}=5^{\circ} \mathrm{C}$ \\
Time: $8-8: 30$ & $\mathrm{Rh}=34 \%$ & $\mathrm{~W}=40 \mathrm{Km} / \mathrm{h}$ \\
am & $\mathrm{Rv}=0.26 \mathrm{~ms}^{-1}$ & $\mathrm{~N}=62 \%$ \\
Ps: $\mathrm{E}=1$ & $\mathrm{Clo}=0.7 \mathrm{clo}$ & $\mathrm{P}=4.5 \mathrm{~mm}$ \\
$\mathrm{Ac}=1.2$ met & $\mathrm{Ac}=1.2$ met & \\
\hline
\end{tabular}

After we implement the different data in the fusion algorithm based on the belief theory, we have the pignistic probabilities of each block as presented in Table 5.

Table 5. First fusion level of the scenario No.1

\begin{tabular}{lll}
\hline B1: & $\operatorname{BetP}(\mathrm{O})=0.0768$ & $\operatorname{BetP}(\mathrm{Un})=0.1953$ \\
& $\begin{array}{l}\operatorname{BetP}(\mathrm{Su})=0.7173 \\
\\
\mathrm{~m}(\varnothing)=0.3359\end{array}$ & $\operatorname{BetP}(\mathrm{So})=0.0105$ \\
B2: & $\operatorname{BetP}(\mathrm{TC})=0.0222$ & $\operatorname{BetP}(\mathrm{Comf})=0.972$ \\
& $\operatorname{BetP}(\mathrm{TH})=0.0051$ & $\mathrm{~m}(\varnothing)=0.3686$ \\
B3: & $\operatorname{BetP}(\mathrm{H})=0.0146$ & $\operatorname{BetP}(\mathrm{C})=0.9003$ \\
& $\operatorname{BetP}(\mathrm{N})=0.0852$ & $\mathrm{~m}(\varnothing)=0.2688$ \\
\hline
\end{tabular}

According to the pignistic probabilities obtained after the first fusion level, we assume that the room will be soon unoccupied $(\mathrm{BetP}(\mathrm{Su})=0.7173)$. The weather is cold outside $(\operatorname{BetP}(C)=0.9003)$ but the thermal comfort is reached indoor $(\mathrm{BetP}(\mathrm{Comf})=$ 0.9727). The conflict mass for each block is less than $40 \%$, so we can conclude that our system provides a satisfactory data fusion. The second fusion level of these results yields the pignistic probabilities presented in Table 6 .

Table 6. Second fusion level of the scenario No.1

\begin{tabular}{llll}
\hline BetP $(\operatorname{Inc})=$ & $\operatorname{BetP}(\operatorname{Dec})=$ & $\operatorname{BetP}(\mathrm{St})=$ & $\mathrm{m}(\varnothing)=$ \\
0.0095 & 0.7036 & 0.2868 & 0.8344 \\
\hline
\end{tabular}

The results in Table 6 reveal that the temperature needs to be decreased as $\operatorname{BetP}(\mathrm{Dec})=0.7036$. At first sight, this makes sense because the room will be unoccupied in less than 30 minutes according to the 
occupancy planning $(\mathrm{BetP}(\mathrm{Su})=0.7173)$. However, the conflict mass is relatively significant which is normal because the system tries to maintain the best comfort ambience for the occupant since he has not left the house yet and because the outside temperature is relatively cold $(\operatorname{BetP}(\mathrm{C})=0.9)$. This is translated in the system as $\operatorname{BetP}(\mathrm{St})=0.2868$ and hence increases the conflict mass. One means to decrease the conflict would be to set, for example, energy saving as a priority, thereby diminishing the influence of the comfort parameter (discounting $\boldsymbol{\alpha}$ ) in accordance with the given context.

\subsection{Scenario no. 2}

This scenario presents a specific configuration in which we preheat the house progressively for half an hour before the occupant arrives for his lunch break. We process this way to smoothly prepare a comfortable ambience for the occupant and save energy at the same time. Table 7 presents the different parameters of the second scenario. It should be noted that the activity and the clothing of the occupant are no longer taken into account in this simulation because the occupant is not in the house $(\mathrm{E}=0)$.

Table 7. Parameters of the second scenario

\begin{tabular}{|l|l|l|}
\hline B1: Occupancy & $\begin{array}{l}\mathrm{B} 2 \text { : Thermal } \\
\text { comfort }\end{array}$ & $\begin{array}{r}\mathrm{B} \text { 3: Weather } \\
\text { forecast }\end{array}$ \\
\hline Day: Monday & $\mathrm{Tc}=16^{\circ} \mathrm{C}$ & $\mathrm{T}=6^{\circ} \mathrm{C}$ \\
Time: $12: 30-13: 00$ am & $\mathrm{Rh}=55 \%$ & $\mathrm{~W}=37 \mathrm{~km} / \mathrm{h}$ \\
Ps: $\mathrm{E}=0$, & $\mathrm{Rv}=0.5 \mathrm{~ms}^{-1}$ & $\mathrm{~N}=65 \%$ \\
$\mathrm{Ac}=0$ met & $\mathrm{Clo}=0$ clo & $\mathrm{P}=4.5 \mathrm{~mm}$ \\
& $\mathrm{Ac}=0$ met & \\
\hline
\end{tabular}

We will present the masses (Table 8) of the heating system assigned by the expert occupancy which depends on the schedule given by Figure 2 because we cannot fuse the information on the block B1 $(\mathrm{Ac}=0)$.

Table 8. First fusion level of the scenario No.2

\begin{tabular}{lll}
\hline B1: & $\mathrm{m}(\mathrm{In})=0.67$ & $\mathrm{~m}(\operatorname{Dec})=0.07$ \\
& $(\mathrm{St})=0.16$ & $\mathrm{~m}(\varnothing)=0.3359$ \\
B2: & $\operatorname{BetP}(\mathrm{TC})=0.7669$ & $\operatorname{BetP}(\mathrm{Comf})=0.224$ \\
& $\operatorname{BetP}(\mathrm{TH})=0.0087$ & $\mathrm{~m}(\varnothing)=0.4760$ \\
B3: & $\operatorname{BetP}(\mathrm{H})=0.0145$ & $\operatorname{BetP}(\mathrm{C})=0.9003$ \\
& $\operatorname{BetP}(\mathrm{N})=0.1325$ & $\mathrm{~m}(\varnothing)=0.2647$ \\
\hline
\end{tabular}

The house is empty since $(\mathrm{E}=0)$ but will be soon occupied $(\mathrm{m}(\mathrm{So})=0.6)$. The pignistic probabilities show that the weather is cold $(\operatorname{Bet} \mathrm{P}(\mathrm{C})=0.853)$ which is obvious as it is winter (Northern Europe). The internal environment is cold because the SPHS maintains the heating at the minimum $\left(16^{\circ} \mathrm{C}\right.$, "Eco Mode") when the house is empty. The second fusion level results are given in Table 9.

Table 9. $2^{\text {nd }}$ fusion level of the scenario No.2

\begin{tabular}{llll}
\hline $\operatorname{BetP}(\operatorname{Inc})=$ & $\operatorname{BetP}($ Dec $)=$ & $\operatorname{BetP}(\mathrm{St})=$ & $\mathrm{m}(\varnothing)=$ \\
0.9574 & 0.0089 & 0.0337 & 0.4059 \\
\hline
\end{tabular}

The decision for this scenario is to increase the temperature to have a comfortable environment for the occupant's arrival. The aim of this is to progressively launch the heating half an hour before an occupancy period to avoid a sudden launch of the system when the occupant arrives thus avoiding an additional loss in energy (temperature overshoot).

This scenario will be split into three parts; in each one we will present a different scenario at the time slot of the same day. The aim of this scenario is to observe the impact of an unexpected event on our data fusion system. That's why we assume that the occupant will be an hour and a half late for what is planned in the schedule (Figure 2).

\subsubsection{Scenario no 3.1 - Without any unforeseen events}

In this scenario, we will preheat the room progressively, half an hour before the occupant's arrival to prepare a comfortable atmosphere in the house. This scenario's data are presented in Table 10 and the pignistic probabilities of each fusion block in Table 11.

Table 10. Parameters of the scenario No.3.1

\begin{tabular}{|l|l|l|}
\hline B1: Occupancy & $\begin{array}{l}\mathrm{B} 2: \text { Thermal } \\
\text { comfort }\end{array}$ & $\begin{array}{l}\mathrm{B} \text { 3: Weather } \\
\text { forecast }\end{array}$ \\
\hline Day : Monday & $\mathrm{Tc}=16^{\circ} \mathrm{C}$ & $\mathrm{T}=11^{\circ} \mathrm{C}$ \\
Time: $06: 30-$ & $\mathrm{Rv}=0.4 \mathrm{~ms}^{-1}$ & $\mathrm{~W}=13 \mathrm{~km} / \mathrm{h}$ \\
07:00 pm & $\mathrm{Rh}=55 \%$ & $\mathrm{~N}=13 \%$ \\
Ps: $\mathrm{E}=0$ & $\mathrm{Clo}=0 \mathrm{clo}$ & $\mathrm{P}=2.5 \mathrm{~mm}$ \\
Ac $=0$ met & $\mathrm{Ac}=0 \mathrm{met}$ & \\
\hline
\end{tabular}

Table 11. First fusion level of the scenario No.3.0.1

\begin{tabular}{|c|c|c|}
\hline B1: & $\begin{array}{l}\mathrm{m}(\mathrm{Inc})=0.6900 \\
\mathrm{~m}(\mathrm{St})=0.1200\end{array}$ & $\begin{array}{l}\mathrm{m}(\mathrm{Dec})=0.0900 \\
\mathrm{~m}(\Omega)=0.1\end{array}$ \\
\hline B2: & $\operatorname{BetP}(\mathrm{TC})=0.5927$ & $\operatorname{Bet} \mathrm{P}(\mathrm{Conf})=0.3983$ \\
\hline & $\operatorname{BetP}(\mathrm{TH})=0.0090$ & $\mathrm{~m}(\varnothing)=0.4928$ \\
\hline B3: & $\begin{array}{l}\operatorname{BetP}(H)=0.1507 \\
\operatorname{BetP}(N)=0.6385\end{array}$ & $\begin{array}{l}\operatorname{BetP}(C)=0.2107 \\
\mathrm{~m}(\varnothing)=0.2709\end{array}$ \\
\hline
\end{tabular}

We notice that the weather is nice $(\operatorname{BetP}(\mathrm{N})=$ $0.6385)$. The house is cold $(\operatorname{BetP}(\mathrm{TC})=0.5927)$ because it was unoccupied since 1:30 pm but it will be soon occupied (So) according to the schedule in Figure $2(\mathrm{~m}(\mathrm{So})=0.7)$ 
Table 12. $2^{\text {nd }}$ fusion level of the scenario No.3.1

\begin{tabular}{llll}
\hline BetP(Inc) & BetP(Dec) & BetP(St) $=$ & $\mathrm{m}(\varnothing)=$ \\
$=0.8072$ & $=0.0439$ & 0.1489 & 0.6673 \\
\hline
\end{tabular}

After the simulation of the second fusion level, the results confirm our expectations so that we should increase the heating temperature $(\operatorname{BetP}(\operatorname{Inc})=0.8072)$ to achieve a comfortable environment. However, we notice that the conflict mass is relatively important because we are in a transition state, where the room is not occupied yet, but will be very soon and preheating is essential to achieve the comfort.

\subsubsection{Scenario no. 3.2 - The occupant's arrival has been delayed}

The occupant did not come home as planned in the schedule at 7:00 p.m., so we have an unexpected case scenario. We preheat the house between 06:30-07:00 pm but since the occupant is late, we will observe the results of the algorithm in this case. The data for this scenario are presented in Table 13.

Table 13. Parameters of the scenario No. 3.2

\begin{tabular}{|l|l|l|}
\hline B1: Occupancy & $\begin{array}{l}\mathrm{B} 2: \text { Thermalcomf } \\
\text { ort }\end{array}$ & $\begin{array}{l}\mathrm{B} 3 \text { : Weather } \\
\text { forecast }\end{array}$ \\
\hline $\begin{array}{l}\text { Day:Monday } \\
\text { time:8-8:30 pm }\end{array}$ & $\begin{array}{l}\mathrm{Tc}=17^{\circ} \mathrm{C} \mathrm{Rv}= \\
0.4 \mathrm{~ms}^{-1}\end{array}$ & $\mathrm{~T}=9{ }^{\circ} \mathrm{C}$ \\
exactly at $8: 18 \mathrm{pm}$ & $\mathrm{Wh}=55 \%$ & $\mathrm{~N}=13 \%$ \\
Ps : $\mathrm{E}=0$ & $\mathrm{Clo}=0$ clo & $\mathrm{P}=2.5 \mathrm{~mm}$ \\
$\mathrm{Ac}=0$ met & $\mathrm{Ac}=0$ met & \\
\hline
\end{tabular}

After we implement the different data in the fusion algorithm based on the belief theory, we obtain the pignistic probabilities of each fusion block as in Table 14. The house is unoccupied $(\mathrm{E}=0)$ and the pignistic probabilities indicate that the weather is relatively cold $(\operatorname{Bet} P(C)=$ 0.4299 and $\operatorname{BetP}(\mathrm{N})=0.4043)$ and the internal ambience is quite cold $(\mathrm{BetP}(\mathrm{TC})=0.5002)$. Indeed the internal environment is cooling down $(\operatorname{BetP}(\mathrm{Comf})=0.4906)$ because we preheated the room between 6:30 and 7:00 pm but since the occupant did not come home yet, the internal temperature begins to decrease, hence the conflict mass of the thermal comfort

Table 14. First fusion level of the scenario No. 3.2

\begin{tabular}{|c|c|c|}
\hline \multirow{2}{*}{ B1: } & $\mathrm{m}(\operatorname{Inc})=0.1$ & $\mathrm{~m}(\mathrm{Dec})=0.35$ \\
\hline & $\mathrm{m}(\mathrm{St})=0.45$ & $\mathrm{~m}(\Omega)=0.1$ \\
\hline \multirow[b]{2}{*}{ B2: } & $\operatorname{BetP}(\mathrm{TC})=0.5002$ & $\operatorname{Bet} P(\operatorname{Conf})=0.4906$ \\
\hline & $\operatorname{BetP}(\mathrm{TH})=0.0092$ & $\mathrm{~m}(\varnothing)=0.5022$ \\
\hline \multirow{2}{*}{ B3: } & $\operatorname{BetP}(\mathrm{H})=0.1658$ & $\operatorname{Bet} P(C)=0.4299$ \\
\hline & $\operatorname{Bet} P(N)=0.4043$ & $\mathrm{~m}(\varnothing)=3373$ \\
\hline
\end{tabular}

expert is relatively high and it is a consequence of this unexpected event (delay) that implies an unplanned transition state.

Table 15. $2^{\text {nd }}$ fusion level of the scenario No.3.2

\begin{tabular}{llll}
\hline BetP(Inc) & BetP(Dec) & BetP(St) $=$ & $\mathrm{m}(\varnothing)=$ \\
$=0.2940$ & $=0.1803$ & 0.5257 & 0.7599 \\
\hline
\end{tabular}

The final decision will be to "maintain stable" the temperature $(\operatorname{BetP}(\mathrm{St})=0.5257)$ at the lower value of $16^{\circ} \mathrm{C}$, because the house is still empty and we do not have further information about the occupant's estimated time of arrival. This explains the important conflict mass generated in this scenario. This tells us that the decision is tremendously risky. The pignistic probability $\operatorname{BetP}(\operatorname{Inc})=30 \%$ is not considered whereas the occupant could arrive at any moment and the temperature won't be comfortable. Figure 4 shows the result window of Matlab simulation program (DST library). It is extremely important to deal with this type of scenario as it requires a decision on the temperature regulation strategy. So should the priority be placed on the occupant's comfort or on the energy savings? It would be recommended to give the user the control over the choice of strategy as a feeling of discomfort could compromise the use of the system.

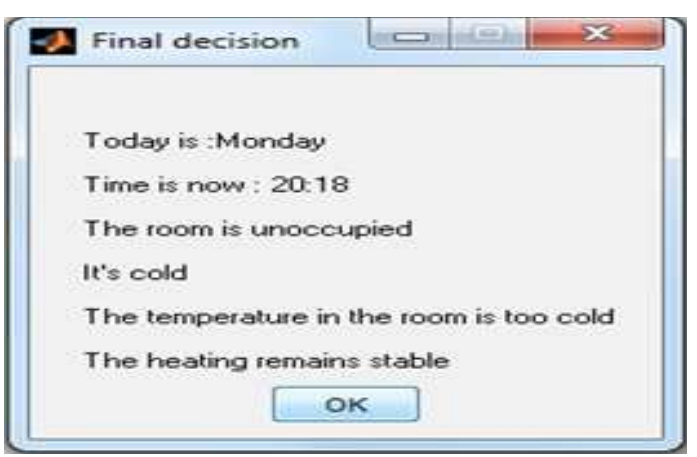

Figure 4. Results window of scenario No.3.2

\subsubsection{Scenario no 3.3 - Occupant arrival}

This scenario is the continuity of the previous one presented, when the occupant arrives at $8: 28 \mathrm{pm}$.

The fusion of the data in Table 16 yields the pignistic probabilities which confirms that the occupant has arrived home $(\operatorname{BetP}(\mathrm{O})=0.979)$. However, the internal environment is cold $(\operatorname{BetP}(\mathrm{TC})=0.7170)$ so he is in a "discomfort" situation. This is a normal consequence since the occupant is late and the preheat period ended at 7:00 pm so the heating system maintains the minimum value $16^{\circ} \mathrm{C}$ as we concluded in section 5.3.2. This also explains 
the latent conflict mass since the occupant expected a comfortable environment at home but it was too cold.

Table 16. Parameters of the scenario No.3.3

\begin{tabular}{|l|l|l|}
\hline B1: Occupancy & \multicolumn{1}{|c|}{$\begin{array}{c}\text { B2:Thermal } \\
\text { comfort }\end{array}$} & $\begin{array}{l}\mathrm{B} \text { 3:Weather } \\
\text { forecast }\end{array}$ \\
\hline Day: Monday & $\mathrm{Tc}=17^{\circ} \mathrm{C}$ & $\mathrm{T}=9^{\circ} \mathrm{C}$ \\
Time:8-8:30 pm & $\mathrm{Rv}=0.4 \mathrm{~ms}^{-1}$ & $\mathrm{~W}=13 \mathrm{~km} / \mathrm{h}$ \\
Occupant arrives at & $\mathrm{Rh}=55 \%$ & $\mathrm{~N}=13 \%$ \\
\hline 8:28 pm & $\mathrm{Clo}=1$ clo & $\mathrm{P}=2.5 \mathrm{~mm}$ \\
\hline Ps: $\mathrm{E}=1, \mathrm{Ac}=1.2$ met & $\mathrm{Ac}=1.2$ met & \\
\hline
\end{tabular}

The second fusion level results (Table 17) show that we should increase the heating temperature $(\mathrm{BetP}(\mathrm{Inc})=0.7931)$ to rectify this discomfort situation $(\operatorname{BetP}(\mathrm{TC})=0.7170)$.

Table 17. $2^{\text {nd }}$ fusion level of the scenario No.3.3

\begin{tabular}{llll}
\hline BetP(Inc) $=$ & BetP(Dec $)=$ & $\operatorname{BetP}($ St $)=$ & $\mathrm{m}(\varnothing)=$ \\
0.7931 & 0.0045 & 0.2024 & 0.6757 \\
\hline
\end{tabular}

\section{Comparison with Probabilities}

In this section we briefly compare and discuss the example from $\S 5.1$ to the weighted mean of probabilities. A decision based on the weighted mean of probabilities and the belief function decision are similar methods, albeit that the probability combinations are very different. Moreover, the belief function allows dealing with uncertain and conflicting data. In the example below, we use a weighted mean to compare the results presented in Table 6. A key consideration is that probabilities are "committed data"; this means that the probability will tend towards the strongest hypothesis, even when it is questionable $(51 \%$ versus $49 \%$ ). With belief functions the decision is more a compromise, "less committed", as we measure the ignorance and the conflict in the decision. We propose to focus on the data example in $§ 5.1$. To apply probabilities, we need to transform the different FoDs into a single FoD (Increase, Stable, Decrease) to be able to calculate a weighted mean. For the weather forecast we apply the equations system in equation 9. The other probabilities are read directly from the respective BBA. The weights are distributed arbitrarily but still respect the data importance stated in the architecture proposed in Figure 1. The most important information is the "Comfort Temperature" and the "Occupation Schedule", which is translated into a heavier weight. In the results presented in the table below, we can notice that the decision moves to "Stable" (55\%) instead of "Decrease". "Stable" is not a proper decision because the inhabitants leave 30 minutes later. In the section $\S 5.1$, we see that the hypothesis "Stable" has importance but the hypothesis "Decrease" is the highest. This contradictory statement is highlighted by the level of the conflict measurement. If we reproduce the previous calculation (weighted mean) on the different study cases presented in this article, we will probably observe the same "bad" decision when the scenarios present unexpected events.

\section{Conclusion}

In this paper we presented a fusion method based on the TBM in order to produce a "temperature trend" that controls a "Smart and Predictive Heating Controller". This trend is a result of a multilevel fusion strategy based on the TBM that analyses and fuses heterogeneous and uncertain data, provided by three sources "Occupancy", "Thermal comfort" and "Weather forecast". We proposed the main "real-life" scenarios and the simulation of which provided encouraging and coherent decisions, despite the significant conflict mass and the complexity of the data. Moreover, we introduced a more important number of sources than in the classical studies. As the real-life data obtained from laboratory tests are highly erroneous and uncertain, the conflict masses will rise, especially in the cases of unexpected events. However, the diverse results also show the potential of including a predictive temperature trend in a heating system in order to reduce electricity consumption. This first study demonstrates the reliability and the potential efficiency of our fusion strategy. In our upcoming project, we aim to reduce the conflict masses.

Table 19. Weighted mean of probabilities, data from Table 4.

\begin{tabular}{|c|c|c|c|c|c|c|c|c|c|}
\hline weights & 0,20 & 0,13 & 0,05 & 0,04 & 0,05 & 0,13 & 0,36 & 0,05 & 1,00 \\
\hline Temp Trend & $\begin{array}{c}\text { Conf Temp } \\
(\mathrm{Tc}=22)\end{array}$ & $\begin{array}{c}\text { Acrivity } \\
(\mathrm{Ac}=1,2)\end{array}$ & $\begin{array}{c}\text { Clothing } \\
(\mathrm{Clo}=0,8)\end{array}$ & $\begin{array}{c}\text { Air velocity } \\
(\mathrm{Rv}=0,18)\end{array}$ & $\begin{array}{c}\text { Air Humidity } \\
(\mathrm{Rh}=35)\end{array}$ & $\begin{array}{c}\text { Occupat }^{\circ} \\
(\mathrm{Ac})\end{array}$ & $\begin{array}{c}\text { Schedule } \\
(\mathrm{Sc})\end{array}$ & Weather & Mean \\
\hline Increase & 0,050 & 0,050 & 0,050 & 0,390 & 0,100 & 0,150 & 0,025 & 0,900 & $\mathbf{0 , 1 1 2}$ \\
\hline Decrease & 0,050 & 0,050 & 0,050 & 0,000 & 0,100 & 0,075 & 0,850 & 0,015 & $\mathbf{0 , 3 4 0}$ \\
\hline Stable & 0,900 & 0,900 & 0,900 & 0,610 & 0,800 & 0,775 & 0,125 & 0,085 & $\mathbf{0 , 5 4 8}$ \\
\hline
\end{tabular}




\section{REFERENCES}

1. CANTIN, R., B. MOUJALlED, G. GUARRACINO, Complexity of Thermal Comfort in Buildings, European Conference of Science (6), 2005.

2. CDC CLIMATE RESEARCH, Key Figures on Climate France and Worldwide 2015. http://www.cdcclimat.co m/IMG//pdf/1410_reperes_2015_eng-hd.pdf, Accessed 05 June 2015.

3. DALY, D., P. COOPER, P. Z. MA, Understanding the Risks and Uncertainties Introduced by Common Assumptions in Energy Simulations for Australian Commercial Buildings. Energy and Buildings, 75, 2014, 382-393.

4. DOUNIS, A. I., M. BRUANT, M. J. SANTAMOURIS, G. GUARRANCINO, P. MICHEL, Comparison of Conventional and Fuzzy Control of Indoor Air Quality in Buildings. J. Intell. \& Fuz. Syst., 42, 1996, 131-40.

5. FISCHER, C. Feedback on Household Electricity Consumption: A Tool for Saving Energy. En. Eff., 1, 2008, 79-104.

6. KALOGIROU, S. A., Applications of Artificial Neural Networks in Energy Systems, A Review, Energy Conversion \& Management, 40, 1999, 1073-1087.

7. KIM, S., J. H. LEE, J. W. MOON, Performance Evaluation of Artificial Neural Network-based Variable Control Logic for Double Skin Enveloped Buildings During the Heating Season. Bld. and Envir., 82, 2014, 328-338.

8. LAZOS, D., A. SPROUL, M. KAY, Optimization of Energy Management in Commercial Buildings with Weather Forecasting Inputs: A Review, Ren. \& Sust. Energy Reviews, 39, 2014, 587-603.

9. LE, C. A., V.-N. HUYNH, SHIMAZU, A. Y. NAKAMORI, Combining Classifiers for Word Sense Disambiguation based on Dempster-Shafer's Theory and OWA Operators. D. \& K. Eng., 63(2), 381-396.

10. MARHIC, B., L. DELAHOCHE, C. SOLAU, A.-M. JOLLY-DESODT, V. RICQUEBOURG, An Evidential Approach for Detection of Abnormal Behavior in the Presence of Unreliable Sensors. Inf. Fus., 13, 2012, 146-160.
11. MARVUGLIA, A., A. MESSINEO, G. NICOLOSI, Coupling a Neural Network Temperature Predictor and a Fuzzy Logic Controller to Perform Thermal Comfort Regulation in an Office Building. Bldg. \& Env., 72, 2014, 287-299.

12. MERCIER, D., G. CRON, T. DENEOUX, M. H. MASSON, Decision Fusion for Postal Address Recognition using Belief Functions. Expert Systems with Applications, 36, 2009, 5643-5653.

13. MISSAOUI, R., JOUMAA, H., PLOIX, S., BACHA, S. Managing Energy Smart Homes According to Energy Prices: Analysis of a Building Energy Management System, En. \& Bldg., 71, 2014, 155-167.

14. MOLLE, D. P. M. PATRY, RT 2012 et RT existant réglementation thermique et efficacité énergétique. Ed.: Eyrolles, 2011.

15. MOROŞAN, P.-D., R. BOURDAISA, D. DUMURB, J. BUISSONA, Building Temperature Regulation using A Distributed Model Predictive Control. En. and Buildings, 42, 2010, 1445-1452.

16. OECD/IEA, Technology Roadmap Energy-Efficient Buildings: Heating and Cooling Equipment, 2011, France.

17. OLDEWURTEL, F., A. PARISIO, C. N. JONES, D. GYALISTRAS, M. GWERDER, V. STAUCH, B. LEHMANN, M. MORARI, Use of Model Predictive Control and Weather Forecasts for Energy Efficient Building Climate Control. En. \& Bldg., 45, 2012, 15-27.

18. SEITY, Y., P. BROUSSEAU, S. MALARDEL, G. HELLO, P. BÉNARD, F. BOUTTIER, C. LAC, V. MASSON, The Arome-France Convective Scale Operational Model. Monthly Weather Review, 139, 2011, 976-991.

19. SHAFER, G., A Mathematical Theory of Evidence USA, Princeton Univ., 1976.

20. SMETS, P., R. KENNES, The Transferable Belief Model. AI, 66, 1994, 191-234.

21. ZHAO, J., B. LASTERNAS, K. P. LAM, R. YUN, V. LOFTNESS, Occupant Behavior and Schedule Modeling for Building Energy Simulation through Office Appliance Power Consumption Data Mining. En. \& Bld., 82, 2014, 341-355. 